\title{
Acquired Methemoglobinemia Associated with Topical Lidocaine Administration: A Case Report
}

\author{
Hawkins C. Gay ${ }^{1,2}$ - Ansel Philip Amaral ${ }^{1}$
}

Published online: 7 April 2018

(C) The Author(s) 2018

\begin{abstract}
A 55-year-old male was admitted to the hospital with pneumonia. During an intubation procedure, the patient received an application of endobronchial lidocaine (4\% gel). Within $2 \mathrm{~h}$ of intubation, the patient developed worsening hypoxia, and investigation of arterial blood gasses revealed a $\mathrm{pH}$ of 7.21, carbon dioxide partial pressure $\left(\mathrm{PaCO}_{2}\right)$ of $3.3 \mathrm{kPa}$, oxygen partial pressure $\left(\mathrm{PaO}_{2}\right)$ of $55.1 \mathrm{kPa}$, and measured oxygen saturation of $49 \%$. Cooximetry of this sample returned a methemoglobin level of $53 \%$. Intravenous methylthioninium chloride (1\% solution at $1 \mathrm{mg} / \mathrm{kg}$ ) was delivered, and subsequent arterial blood gasses, at $30 \mathrm{~min}$ and $1 \mathrm{~h}$ post administration, showed methemoglobin levels of 12 and $9 \%$, respectively, with return of oxygen saturation to $>90 \%$.
\end{abstract}

Hawkins C. Gay

hawkins.gay@northwestern.edu

1 Northwestern University Feinberg School of Medicine, Chicago, IL, USA

2 McGaw Medical Center of Northwestern University, 251 East Huron Street, Galter Suite 3-150, Chicago, IL 60611, USA

\section{Key Points}

Topical lidocaine and other commonly used local anesthetics have a poorly recognized though wellassociated risk of acquired methemoglobinemia.

Acquired methemoglobinemia should be considered in any patient with a divergence in measured oxygen saturation and arterial oxygen partial pressure.

Intravenous methylthioninium chloride ( $1 \%$ solution at $1 \mathrm{mg} / \mathrm{kg}$ ) acts as a rapid iron-reducing agent and is the most effective therapy for acquired methemoglobinemia.

\section{Background}

Methemoglobin is formed when ferrous iron $\left(\mathrm{Fe}^{2+}\right)$ undergoes oxidation to produce ferric iron $\left(\mathrm{Fe}^{3+}\right)$, which is unable to bind oxygen [1]. Under circumstances of oxidative stress, or when exposed to oxidizing agents, the body's protective mechanisms may not be able to maintain hemoglobin homeostasis, and methemoglobin levels can rise above the upper reference range of $2 \%$. The pathologic effects of this process include (1) a shift of the oxygen-hemoglobin dissociation curve to the left, resulting in decreased release of oxygen to the tissue, a phenomenon known as the DarlingRoughton effect; and (2) functional anemia due to the inability of methemoglobin to bind oxygen, ultimately resulting in the disease state known as methemoglobinemia [1]. The primary risk of methemoglobinemia is tissue 
Fig. 1 Arterial blood gas (ABG) sample in a patient with acquired methemoglobinemia $\mathbf{a}$ before and $\mathbf{b}$ after treatment with methylthioninium chloride. $I C U$ intensive care unit, $I V$ intravenous
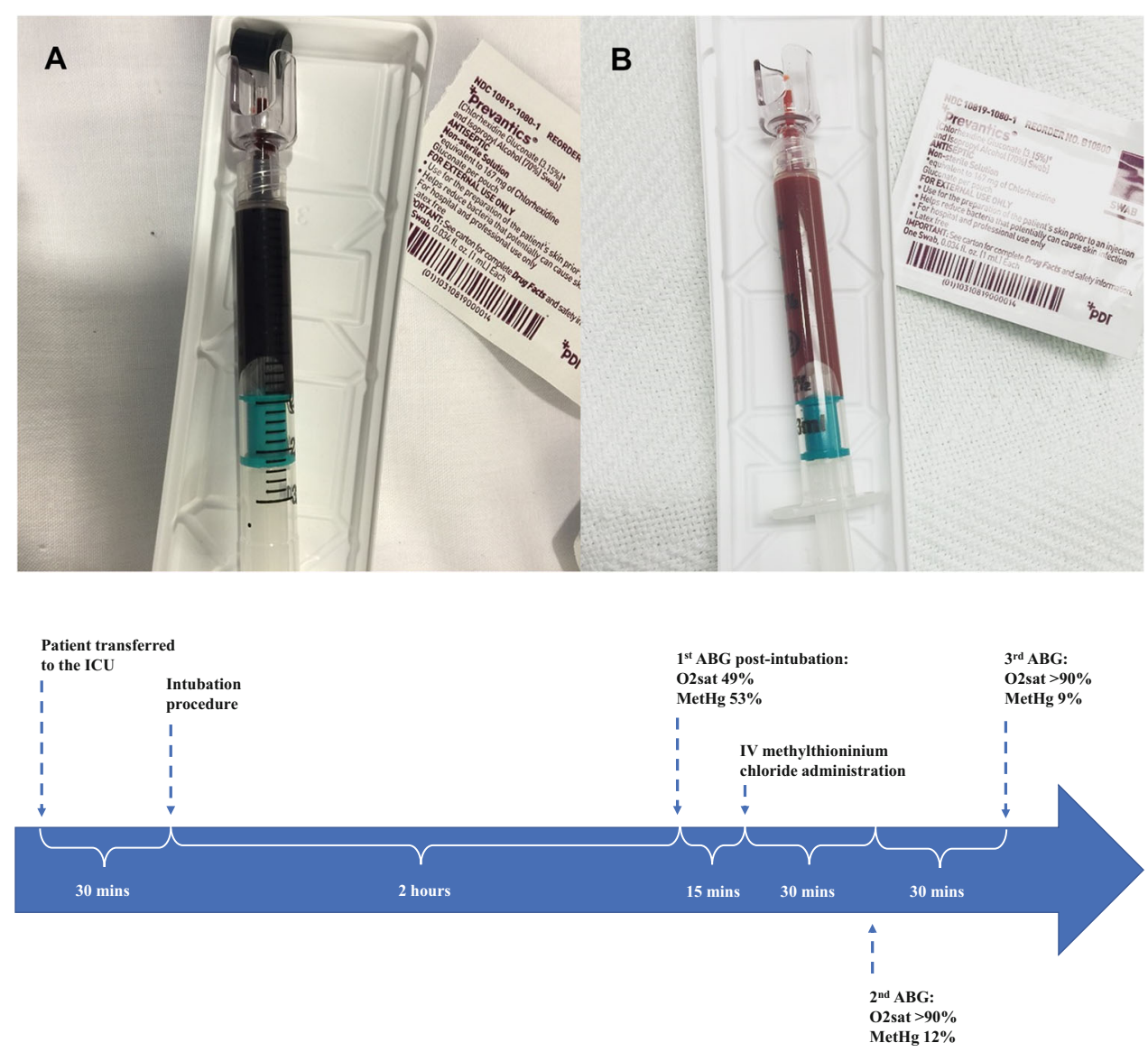

hypoxia and cyanosis, which can lead to acidosis, seizures, arrhythmias, and-if prolonged-cardiovascular collapse and death. Classic features of methemoglobinemia include a characteristically brown coloration to the arterial blood, a large difference in the measured and calculated oxygen saturations $\left(\mathrm{O}_{2}\right.$ sat) (known as the saturation gap), and low measured $\mathrm{O}_{2}$ sat in the setting of normal to elevated oxygen partial pressures $\left(\mathrm{PaO}_{2}\right)$ [2]. These risks are increased in the setting of preexisting anemia, when the body's oxygen-carrying capacity is already reduced [3].

\section{Objective}

Our objective is to alert clinicians, pharmacists and other medical care providers to methemoglobinemia, a rare but well-documented side effect of local anesthetics commonly encountered on medical wards.

\section{Case}

A 55-year-old male with a history of multiple myeloma (MM), previous stem cell transplant and recurrence of disease presented to the hospital. He had recently started treatment of relapsed MM with carfilzomib and had developed intermittent fevers 2 days before presentation. $\mathrm{He}$ also complained of dyspnea and a productive cough, which had been present for 3 days before the onset of fever. On admission examination, he was febrile, tachypneic, and tachycardic but alert and fully oriented with a normal blood pressure. He had decreased breath sounds in the right lung base, without rales or wheezing, and the rest of his examination was unremarkable. His initial laboratory analysis was notable for pancytopenia with a white blood cell count of $1.2 \times 10^{9} / 1$, hemoglobin of $53 \mathrm{~g} / \mathrm{l}$ and platelets of $4.0 \times 10^{9} / \mathrm{l}$. He was admitted to the hospital and treated with cefepime and azithromycin for presumed pneumonia; further home medications continued during admission included acyclovir, allopurinol, fluconazole and pantoprazole. Shortly after admission, he developed newonset hypoxia and hypotension with altered mental status. $\mathrm{He}$ was transferred to the medical intensive care unit, where laboratory analysis revealed a lactic acid of $6.1 \mathrm{mMol} / \mathrm{l}$ and an initial arterial blood gas (ABG) returned a pH of 7.40, carbon dioxide partial pressure $\left(\mathrm{PaCO}_{2}\right)$ of $3.3 \mathrm{kPa}, \mathrm{PaO}_{2}$ of $11.3 \mathrm{kPa}$, and measured $\mathrm{O}_{2}$ sat of $94 \%$. During an intubation procedure, the patient was treated with topical endobronchial lidocaine (4\% gel applied with tongue blade) as well as intravenous etomidate and 
succinylcholine. Roughly $2 \mathrm{~h}$ post-intubation, he became increasingly hypoxic while on $100 \%$ fraction of inspired oxygen $\left(\mathrm{FiO}_{2}\right)$. A repeat $\mathrm{ABG}$ was notably brownish in color (Fig. 1a) and returned a pH of 7.21, $\mathrm{PaCO}_{2}$ of $3.3 \mathrm{kPa}, \mathrm{PaO}_{2}$ of $55.1 \mathrm{kPa}$, and measured $\mathrm{O}_{2}$ sat of $49 \%$. Co-oximetry was requested given the divergence in $\mathrm{PaO}_{2}$ and $\mathrm{O}_{2}$ sat, which revealed a methemoglobin level of $53 \%$. Intravenous methylthioninium chloride (a dose of $1 \%$ solution at $1 \mathrm{mg} / \mathrm{kg}$ ) was delivered and subsequent ABGs, at $30 \mathrm{~min}$ and $1 \mathrm{~h}$ post administration, showed methemoglobin levels of 12 and $9 \%$, respectively, with return of $\mathrm{O}_{2}$ sat to $>90 \%$ and bright red coloration to the ABG sample (Fig. 1b). Figure 2 shows a detailed timeline of these events. Unfortunately, despite recovering from acute methemoglobinemia, the patient ultimately succumbed to septic shock secondary to bacteremia with Rothia mucilaginosa.

\section{Discussion}

The most common cause of acquired methemoglobinemia in the clinical setting is medication administration. Although rare, methemoglobinemia secondary to local and topical lidocaine administration has been documented and described in the medical literature; whether endobronchial application increases this risk is unknown [4]. Reports in the literature describe a greater risk of methemoglobinemia in patients who are anemic; the mechanism is thought to be related to increased hypoxic stress and nitric oxide production [3]. Pre-existing anemia may place patients at greater risk of complications from methemoglobinemia, further necessitating prompt recognition and intervention. Treatment of methemoglobinemia includes withdrawal of the offending agent (including removal of any remaining topical applicant), supportive care with $100 \% \mathrm{O}_{2}$ therapy and circulatory support, as well as reversal of methemoglobin back to hemoglobin. The final therapy is generally accomplished through the administration of methylthioninium chloride ( $1 \%$ solution at $1 \mathrm{mg} / \mathrm{kg}$ ), which acts as a reducing agent, converting $\mathrm{Fe}^{3+}$ to $\mathrm{Fe}^{2+}$ [1]. This process normally occurs rapidly over the course of 30-60 min and can be confirmed through repeat cooximetry. Ascorbic acid has also been used, though this therapy generally takes much longer and is not a viable option in the setting of acute, acquired methemoglobinemia [1].

\section{Conclusion}

This case highlights the clinical and laboratory features of methemoglobinemia, a well-described though rare and poorly recognized side effect of topical lidocaine administration. Early recognition of methemoglobinemia is of primary importance, as the condition is rapidly reversible with correct treatment but can be serious and even fatal if left untreated; these risks may be enhanced in the setting of preexisting anemia.

Author Contributions All authors contributed equally to the drafting, editing and completion of the manuscript.

\section{Compliance with Ethical Standards}

Conflict of interest Hawkins C. Gay and Ansel Philip Amaral have no conflicts of interest that are directly relevant to the content of this case study.

Funding No sources of funding were used to conduct this study or prepare this manuscript.

Consent to participate Informed consent was obtained from the patient's spouse for publication of this case report. A copy of the written consent may be requested from the corresponding author for review.

Open Access This article is distributed under the terms of the Creative Commons Attribution-NonCommercial 4.0 International License (http://creativecommons.org/licenses/by-nc/4.0/), which permits any noncommercial use, distribution, and reproduction in any medium, provided you give appropriate credit to the original author(s) and the source, provide a link to the Creative Commons license, and indicate if changes were made.

\section{References}

1. Cortazzo JA, Lichtman AD. Methemoglobinemia: a review and recommendations for management. J Cardiothorac Vasc Anesth. 2014;28(4):1043-7.

2. Sharma VK, Haber AD. Acquired methemoglobinemia: a case report of benzocaine-induced methemoglobinemia and a review of the literature. Clin Pulm Med. 2002;9(1):53-8.

3. Hare GM, Mu A, Romaschin A, Tsui AK, Shehata N, Beattie WS, et al. Plasma methemoglobin as a potential biomarker of anemic stress in humans. Can J Anaesth. 2012;59(4):348-56.

4. Guay J. Methemoglobinemia related to local anesthetics: a summary of 242 episodes. Anesth Analg. 2009;108(3):837-45. 